http://ojs.stikes-muhammadiyahku.ac.id/index.php/herbapharma

\title{
FORMULASI SEDIAAN SHAMPO EKSTRAK DAUN PANDAN WANGI (Pandanus amaryllifolius Roxb.) SEBAGAI ANTI KETOMBE DENGAN BASIS NATRIUM CARBOXYMETHYL CELLULOSE BERVARIASI
}

Nur Muslimah Utami, Wawang Anwarudin

Program Studi Farmasi, STIKes Muhammdiyah Kuningan

*E-mail : mualimah.utami@gmail.com

\begin{abstract}
ABSTRAK
Daun pandan wangi (Pandanus Amaryllifolius, Roxb) memiliki kandungan senyawa kimia berupa alkaloid, flavonoid, saponin, polifenol, tannin dan zat warna. Dalam daun pandan wangi senyawa yang dapat memberikan aktivitas antimikroba adalah flavonoid dan polifenol (fenol). Tujuan penelitian ini adalah untuk membuat formulasi sediaan shampo dengan ekstrak daun pandan wangi sebagai zat aktif dan variasi konsentrasi Natrium carboxymethylcellulose ( $\mathrm{Na}-\mathrm{CMC}$ ) sebagai basis untuk memperoleh sediaan shampo yang baik dan mengetahui uji evaluasi shampo dengan konsentrasi basis $\mathrm{Na}$ CMC yang bervariasi. Metode penelitian adalah eksperimental laboratorium. Konsentrasi basis $\mathrm{Na}$ CMC yang digunakan $0.5 \%, 1.5 \%, 2.5 \%$, dan $3 \%$. Hasil penelitian menunjukan sediaan shampo dengan basis Na CMC memenuhi syarat mutu shampo dengan formula yang paling baik adalah Formula 4 dengan konsentrasi $\mathrm{Na} \mathrm{CMC} \mathrm{3 \% .} \mathrm{Jika} \mathrm{dilihat} \mathrm{dari} \mathrm{segi} \mathrm{organoleptis} \mathrm{yaitu} \mathrm{dengan}$ warna kuning kecoklatan, bau khas pandan disertai menthol dan tekstur gel kental, $\mathrm{pH} 6$, sediaan shampo yang didapat homogen dan menghasilkan busa yang paling baik yaitu 10,2 cm pada formula 2. Kesimpulan dari penelitian ini, ekstrak daun pandan wangi dapat diformulasikan sebagai zat aktif dalam pembuatan shampo dengan konsentrasi basis Na CMC sebesar 3\%, serta evaluasi sediaan shampo ekstrak daun pandan wangi (pandanus amaryllifolius, Roxb) dengan konsentrasi Na CMC yang bervariasi memiliki hasil evaluasi yang baik serta memenuhi syarat uji evaluasi sediaan shampo dengan rata-rata $\mathrm{Ph}$ yang diperoleh yaitu 6 memenuhi standar dari SNI 5-9, sediaan shampo yang homogen serta dapat menghasilkan busa dengan baik yaitu $10.2 \mathrm{~cm}$.
\end{abstract}

Kata Kunci :Anti ketombe, Daun pandan wangi, Na CMC, Pandanus amaryllifolius Roxb, Shampo.

\section{ABSTRACT}

Fragrant pandanus leaves (Pandanus Amaryllifolius, Roxb) have the content of chemical compounds in the form of alkaloids, flavonoids, saponins, polyphenols, tannins and color substances. In pandan leaves scented compounds that can provide antimicrobial activity are flavonoids and polyphenols (phenols). The purpose of this study is to make a formulation of shampoo ready with fragrant pandan leaf extract as an active substance and variations in the concentration of Sodium carboxymethylcellulose (Na-CMC) as a basis for obtaining good shampoo content and knowing the evaluation of shampoos with varying concentrations of Na CMC base. The research method is experimental laboratory. The base concentration of Na CMC used is $0.5 \%, 1.5 \%, 2.5 \%$, and $3 \%$. The results showed that shampoos with a Na CMC base qualified for the quality of shampoos with the best formula is Formula 4 with a concentration of Na CMC of $3 \%$. When viewed in terms of organoleptis i.e. with a brownish yellow color, the typical smell of pandan accompanied by menthol and viscous gel texture, $\mathrm{pH} 6$, the shampoo preparedness obtained homogeneously and produces the best foam that is $10.2 \mathrm{~cm}$ in formula 2. The conclusion of this study, fragrant pandan leaf extract can 
be formulated as an active substance in the manufacture of shampoos with a base concentration of $\mathrm{Na} \mathrm{CMC}$ of $3 \%$, as well as evaluation of the readyness of fragrant pandan leaves extract (pandanus amaryllifolius, Roxb) with a varied concentration of Na CMC having good evaluation results and qualifying for the shampoo ready evaluation test with an average Ph obtained that is 6 meet the standard of SNI 5-9, the homogeneous shampoo is ready and can produce foam well which is 10.2 $\mathrm{cm}$.

Keywords :Anti dandruff, Fragrant pandan leaves, Na CMC, Pandarus Amaryllifolius Roxb.

\section{PENDAHULUAN}

Rambut adalah sesuatu yang tumbuh dari akar rambut yang berada dalam lapisan dermis.Rambut juga merupakan mahkota bagi setiap orang, hal ini dikarenakan rambut dapat mempengaruhi penampilan seseorang.Fungsi rambut bagi manusia pada umumnya yaitu sebagai pelindung kulit kepala, pertanda status sosial, identitas profesi dan penunjang penampilan (Tresna, 2010). Gangguan kulit pada rambut kepala seperti sensitif, berminyak dan berketombe, yang mengganggu pertumbuhan rambut secara normal, sehingga mengakibatkan seseorang tidak percaya diri akan penampilannya (Limbani et al.,2009).

Diketahui bahwa lebih dari $60 \%$ populasi di dunia mengalami permasalahan pada rambut yang berketombe. Prevalensi populasi masyarakat Indonesia yang mempunyai masalah ketombe berdasarkan data yang diambil dari International Date Base, US Sensus Bureau tahun 2004 sebesar 43.833.262 dari 238.452.952 jiwa dan menempati urutan ke empat setelah China, India dan US (Sinaga, 2012). Ketombe merupakan salah satu masalah pada kulit kepala dengan gejala seperti tumbuh sisik-sisik putih disertai dengan gatal karena adanya pengelupasan kulit mati (Toruan,1989).

Berbagai macam pengobatan telah banyak dilakukan oleh masyarakat untuk mengatasi masalah ketombe yang dihadapi. Seiring berkembangnya pengobatan di Indonesia, perkembangannya kini mengarah ke sistem pengobatan herbal, karena terbukti lebih aman dan tidak menimbulkan efek samping seperti obat-obat kimia (Mahataranti et al., 2012). Salah satu tanaman herbal yang berkhasiat untuk mengatasi ketombe yaitu daun pandan wangi (pandanus amaryllifolius, Roxb). Menurut Budiman (2012), Kandungan kimia dalam daun pandan wangi yaitu alkaloid, flavonoid, saponin, polifenol, tannin dan zat warna. Dalam daun pandan wangi yang dapat memberikan aktivitas antimikroba adalah flavonoid dan polifenol(fenol) karena senyawa ini akan menghambat tumbuhnya jamur penyebab ketombe (Cowan, 1999 dalam Tritiyanto, 2009).

Menurut penelitian (Lusi nudianti,dkk.2017) yang telah melakukan uji aktivitas ekstrak daun pandan wangi terhadap jamur penyebab ketombe, membuktikan bahwa pada konsentrasi $30 \%$ ekstrak daun pandan wangi dapat berpotensi menghambat pertumbuhan jamur penyebab ketombe dengan daya hambat sebesar $17,80 \mathrm{~mm}$.

Derivat selulosa pada umumnya stabil pada $\mathrm{pH}$ asam, kompatibel dengan elektrolit dan sedikit lebih tahan terhadap kontaminasi bakteri. Salah satu derivat selulosa yang sering digunakan yaitu Carboxymethylcellulose sodium ( $\mathrm{Na} \mathrm{CMC}$ ). $\mathrm{Na} \mathrm{CMC}$ merupakan senyawa anionic yang dapat digunakan sebagai thickening agent atau stabilizing agent (Osol,1980), dapat larut cepat dalam air panas maupun dingin (Lathauwer,2004). Larutan Na CMC stabil pada pH 5-9 (Liebermann, 1996). Peningkatan konsentrasi Na CMC sebagai bahan pengental pada sediaan shampo di duga memiliki hubungan yang kuat terhadap peningkatan viskositas sediaan. Na CMC sering digunakan untuk sediaan oral, topical, beberapa sediaan parenteral serta digunakan secara luas pada sediaan kosmetik dan dinyatakan sebagai bahan tidak beracun dan tidak mengiritasi (Rowe,2009). 


\section{BAHAN DAN METODE}

\section{Bahan dan Alat}

Bahan yang digunakan dalam penelitian ini adalah Daun Pandan Wangi (desa peusing kec. Jalaksana kab.kuningan), Sodium Lauril Sulfat (srilaxmi enterprises), Cocamide DEA, Na CMC, Propil Paraben, Asam Sitrat, Menthol, dan Aquadest.

Peralatan yang digunakan dalam penelitian ini yaitu berupa alat gelas antara lain gelas ukur (iwaki), corong (pyrex), beaker glass (iwaki), Erlenmeyer (iwaki), kaca arloji (supertex), mortir dan stamper (iwaki), cawan penguap, Objek glass, batang pengaduk, $\mathrm{Ph}$ indikator universal (MColorpHast), dan lain sebagainya.

\section{Prosedur Penelitian \\ Determinasi Tanaman}

Determinasi tanaman daun pandan wangi dilakukan di laboratorium pengujian bahan herbal stikes muhammadiyah kuningan

\section{Pembuatan Simplisia Daun Pandan Wangi}

Daun pandan wangi segar yang diperoleh dilakukan sortasi basah, untuk memisahkan bahanbahan asing dari tanaman. Selanjutnya daun pandan wangi dicuci satu persatu dibawah air mengalir hingga bersih, lalu dirajang atau dipotong kecil-kecil. Daun pandan wangi yang telah dirajang kemudian dikeringkan dengan cahaya matahari secara tidak langsung selama 3 hari, lalu dilakukan sortasi kering untuk memisahkan benda asing dan pengotor lain yang masih tertinggal. Simplisia kemudian diblender hingga diperoleh serbuk simplisia daun pandan wangi yang halus (Depkes, 1989).

\section{Ekstraksi Daun Pandan Wangi}

Metode ekstraksi yang digunakan yaitu maserasi menggunakan pelarut etanol $70 \%$ dengan perbandingan 1:4. Simplisia kering daun pandan wangi sebanyak 500 gram dimasukkan ke dalam wadah maserasi dan ditambahkan pelarut etanol $70 \%$ secukupnya dan biarkan selama kira-kira 10 menit selama proses pembasahan simplisia berlangsung bertujuan untuk penyerapan pelarut ke dalam simplisia. Kemudian tambahkan kembali etanol $70 \%$ hingga $660 \mathrm{ml}$ sampai simplisia terendam seluruhnya. Wadah maserasi ditutup dan disimpan selama 24 jam di tempat yang terlindung dari sinar matahari langsung sambil sesekali diaduk. Kemudian setelah 24 jam, ekstrak disaring lalu dipisahkan antara filtrate dengan ampas menggunakan kertas saring. Ampas tadi di ekstraksi ulang menggunakan pelarut etanol $70 \%$ yang baru dengan jumlah yang sama. Hal ini dilakukan selama $3 \times 24$ jam. Filtrate yang dihasilkan kemudian dikumpulkan dan diuapkan hingga diperoleh ekstrak kental.

\section{Formula Sediaan Shampo}

Formulasi sediaan shampo ekstrak daun pandan wangi dilakukan dengan menggunakan konsentrasi basis $\mathrm{Na} \mathrm{CMC}$ yang bervariasi yaitu $0,5 \%, 1,5 \%, 2,5 \%$, dan $3 \%$, tujuan dibedakan ialah untuk mengetahui evaluasi sediaan jadi jika bahan pengental yaitu $\mathrm{Na}$ CMC dibedakan.

Tabel 1. Formulasi Sediaan Shampo dari Ekstrak Daun Pandan Wangi

\begin{tabular}{lcccc}
\hline \multicolumn{1}{c}{ Bahan } & \multicolumn{4}{c}{ Formula (\%) } \\
\cline { 2 - 5 } & $\mathbf{1}$ & $\mathbf{2}$ & $\mathbf{3}$ & 4 \\
\hline Ekstrak DPW & 30 & 30 & 30 & 30 \\
Sodium lauril sulfat & 10 & 10 & 10 & 10 \\
Cocamid DEA & 4 & 4 & 4 & 4 \\
Na CMC & 0,5 & 1,5 & 2,5 & 3 \\
Propil paraben & 0,2 & 0,2 & 0,2 & 0,2 \\
Asam sitrat & 0,1 & 0,1 & 0,1 & 0,1 \\
Menthol & 0,25 & 0,25 & 0,25 & 0,25 \\
Aqua dest & Ad 100ml & Ad 100ml & Ad 100ml & Ad 100ml \\
\hline
\end{tabular}

*Ekstrak DPW : Ekstrak Daun Pandan Wangi 
Pembuatan sediaan shampo dilakukan denganmengembangkan $\mathrm{Na} C \mathrm{CMC}$ dengan aquam terlebih dahulu (M1), lalu larutkan Sodium lauril sulfat dengan aquam sedikit demi sedikit hingga larut di dalam beaker glass (M2), Larutkan menthol dan propil paraben dengan etanol $70 \%$ di dalam erlenmeyer, aduk ad larut (M3), Masukan campuran M2 ke dalam campuran M1 sedikit demi sedikit, aduk perlahan lalu tambahkan cocamid DEA ke dalamnya sedikit demi sedikit sambil di aduk perlahan, Tambahkan campuran M3,lalu masukkan Ekstrak daun pandan wangi, Larutan sampo tersebut ditambahkan Asam sitrat yang telah dilarutkan dengan beberapa tetes etanol $70 \%$ dan diaduk. Masukkan kedalam botol lalu tambahkan aquadest hingga $100 \mathrm{ml}$.

\section{Evaluasi Sediaan}

\section{Uji Organoleptik}

Penampilan fisik shampo harus menarik, homogen, tidak pecah, dan mampu membentuk busa (kumar, 2010). Analisis ini dilakukan dengan mengamati bentuk, bau, dan warna sediaan shampo ekstrak daun pandan wangi.

\section{Uji pH}

Pengukuran $\mathrm{pH}$ sediaan shampo dilakukan dengan cara sediaan shampo di encerkan terlebih dahulu dengan air suling 1:10 lalu ph kertas dicelupkan ke dalam larutan sampai menunjukan warna kemudian diamati warna yang terjadi. Nilai $\mathrm{pH}$ shampo harus memenuhi persyaratan yang telah ditetapkan dalam SNI No. 06-2692-1992 yaitu berkisar 5,0-9,0.

\section{Uji Homogenitas}

Uji homogenitas pada sediaan shampo dilakukan dengan Cara menimbang 0,5 gram shampo yang akan di amati lalu dioleskan pada kaca objek yang kering sehingga menghasilkan lapisan tipis kemudian ditutup menggunakan kaca preparat. Amati apakah sediaan homogen atau tidak (Voight, 1994).

\section{Uji Pengukuran Tinggi Busa}

Uji pengukuran tinggi busa dilakukan untuk mengetahui kemampuan shampo untuk menghasilkan busa terhadap air. Sediaan shampo antiketombe yang mengandung berbagai konsentrasi basis sebanyak 0,1 gram dilarutkan menggunakan $10 \mathrm{ml}$ air ke dalam tabung reaksi lalu ditutup dan dikocok selama 20 detik. Diukur tinggi busa yang terbentuk

\section{HASIL DAN PEMBAHASAN}

\section{Uji Organoleptik}

Tabel 2. Hasil Pengamatan Organoleptik Sediaan Shampo Ekstrak Daun Pandan Wngi

\begin{tabular}{ccccc}
\hline Pengamatan & F1 & F2 & F3 & F4 \\
\hline $\begin{array}{c}\text { Bentuk } \\
\text { Warna }\end{array}$ & Cair & Cair & Gel kental \\
Coklat tua bening & Coklat bening & $\begin{array}{c}\text { Gel kental } \\
\text { Kuning } \\
\text { kecoklatan } \\
\text { bening }\end{array}$ \\
Bau & $\begin{array}{c}\text { Khas pandan } \\
\text { disertai menthol }\end{array}$ & $\begin{array}{c}\text { Khas pandan } \\
\text { disertai menthol }\end{array}$ & $\begin{array}{c}\text { Khas pandan } \\
\text { disertai } \\
\text { menthol }\end{array}$ & $\begin{array}{c}\text { Khas pandan } \\
\text { disertai } \\
\text { menthol }\end{array}$ \\
\hline
\end{tabular}

Hasil pengamatan menunjukkan adanya perbedaan bentuk dan warna pada masing masing formula. Jika dilihat dari syarat uji organoleptis yaitu sediaan shampo harus menarik, homogen, tidak pecah, dan mampu membentuk busa, sehingga pada penelitian ini tiap formula sediaan shampo ekstrak daun pandan wangi memenuhi syarat uji organoleptis. 
Uji pH

Tabel 3. Hasil Pengamatan Uji pH Sediaan Shampo Ekstrak Daun Pandan Wangi

\begin{tabular}{cc}
\hline Formula & Ph \\
\hline F1 & 6 \\
F2 & 6 \\
F3 & 6 \\
F4 & 6 \\
\hline
\end{tabular}

Nilai $\mathrm{pH}$ yang diperoleh stabil untuk semua formula sediaan baik dari formula 1 , formula 2 , formula 3, dan formula 4 . Nilai $\mathrm{pH}$ yang didapat yaitu 6 yang berarti memenuhi syarat untuk sediaan shampo menurut standar SNI yaitu 5-9 dan dinyatakan bahwa konsentrasi $\mathrm{Na}$ CMC yang bervariasi tidak berpengaruh pada $\mathrm{pH}$ sediaan.

\section{Uji Homogenitas}

Tabel 4. Hasil Pengamatan Uji Homogenitas Sedian Shampo Esktrak Daun Pandan Wangi

\begin{tabular}{cc}
\hline Formula & Homogenitas \\
\hline F1 & Homogen \\
F2 & Homogen \\
F3 & Homogen \\
F4 & Homogen
\end{tabular}

Dari hasil pengamatan uji homogenitas terlihat bahwa keempat formula sediaan shampo ekstrak daun pandan wangi tercampur secara homogen dan merata tidak ada partikel partikel zat yang berarti memenuhi syarat uji homogenitas sediaan shampo.

\section{Uji Pengukuran Tinggi Busa}

Tabel 5. Hasil Pengamatan Uji Pengukuran Tinggi Busa Sediaan Shampo Ekstrak Daun Pandan Wangi

\begin{tabular}{cc}
\hline Formula & $\begin{array}{c}\text { Pengukuran Tinggi } \\
\text { Busa }(\mathbf{c m})\end{array}$ \\
\hline F1 & 9.5 \\
F2 & 10.2 \\
F3 & 9.7 \\
F4 & 9.9 \\
\hline
\end{tabular}

Uji pengukuran tinggi busa bertujuan untuk mengetahui kemampuan shampo untuk menghasilkan busa terhadap air. Hasil menunjukan bahwa tinggi busa yang dihasilkan bervariasi yaitu untuk formula 1 sebesar $9.5 \mathrm{~cm}$, formula 2 sebesar $10.2 \mathrm{~cm}$, formula 3 sebesar $9.7 \mathrm{~cm}$, dan formula 4 sebesar $9.9 \mathrm{~cm}$. Diantara keempat formula ini untuk tinggi busa yang baik yaitu formula 2 
dengan nilai tinggi busa sebesar $10.2 \mathrm{~cm}$, karena semakin besar nilai tinggi busa yang dihasilkan maka akan semakin baik.

\section{SIMPULAN}

Dapat disimpulkan bahwa :

1. Ekstrak daun pandan wangi dapat diformulasikan sebagai zat aktif dalam pembuatan shampo dengan konsentrasi basis Na CMC sebesar $3 \%$.

2. Evaluasi sediaan shampo ekstrak daun pandan wangi (pandanus amaryllifolius, Roxb) dengan konsentrasi $\mathrm{Na} \mathrm{CMC}$ yang bervariasi memiliki hasil evaluasi yang baik serta memenuhi syarat uji evaluasi sediaan shampo dengan rata-rata $\mathrm{Ph}$ yang diperoleh yaitu 6 memenuhi standar dari SNI $5-9$, sediaan shampo yang homogen serta dapat menghasilkan busa dengan baik.

\section{REFERENSI}

Budiman, H., 2012. Pandan Wangi (Pandanus amaryllifolius Roxb.).diakses, 18 desember 2019.

Cowan, M.M., 1999, Plant Products as Antimicrobial Agents, Clinical Microbiology Reviews Vol. 12, No. $4: 564-82$.

Kumar, ashok; Rakesh Roshan Mali.2010. Evaluation Of Prepared Shampoo Formulations And To Compare Formulated Shampoo With Marketed Shampoos, International Journal of Pharmaceutical Sciences Review and Research, Volume 3, Issue 1, July-August 2010; Article 025.

Lathauwer,G.D., Rycke,D.D., Duynslager, Annelies, Tanghe, Stijn, 2004. Thickening of Foaming Cosmetic Formulation, Proceeding $6^{\text {th }}$ World Surfactant Congress CESIO.154.Germany.

Liebermann, H.A., Rieger, M.M., dan Banker, G.S., 1996. Pharmaceutical Dosage Forms; Disperse System, volume 1, $2^{\text {nd }}$ edition, 157-158,291. Marcel Dekker,Inc.,New York.

Limbani, M., M.R. Dabhi., M.K. Raval., and N.R. Sheth. 2009. Clear Shampoo: an Important Formulation Aspect with Consideration of the Toxicity of Commonly Used Shampoo Ingredients. Saurashtra University, India.

Lusi. N, Siti. F.A, Nur.A (2017). Pengembangan formulasi sediaan gel rambut antiketombe ekstrak daun pandan wangi (pandanus amaryllifolius, roxb.) Dengan menggunakan viscolam sebagai gelling agent dan uji aktivitasnya terhadap jamur pityrosporum ovale. Prodi S1 Farmasi STIKes Bakti Tunas Husada Tasikmalaya : 464 - 465.

Mahataranti, N., I.Y. Astuti., dan B. Asriningdhiani. 2012. Formulasi Shampo Antiketombe Ekstrak Etanol Seledri (Apium Graveolens L.) dan Aktivitasnya Terhadap Jamur Pityrosporum ovale.Jurnal Pharmacy. 9(2): 128-138.

Rowe, R. C., Sheskey, P. J., and Weller, P. J., 2009, Handbook of Pharmaceutical Excipients, Six Edition, 651, 118, 596, 433, 441-442. London, Pharmaceutical Press.

Sinaga, Ernawati., 2012. Biokimia Dasar. Jakarta Barat: PT. ISFI Penerbitan.

Toruan, T. 1989. Ketombe dan Penanggulangannya.Jakarta : Pustaka.

Tresna, Pipin., 2010. Modul 1 Dasar Rias : Perawatan Kulit Wajah (Facial) Universitas Pendidikan Indonesia : Bandung

Voight, R., 1994, Buku Pengantar Teknologi Farmasi, diterjemahkan oleh Soedani, N., Edisi V, Yogyakarta, Universitas Gadjah Mada Pres. 